\title{
Single-Unit Analysis of Postnatal Olfactory Learning: Modified Olfactory Bulb Output Response Patterns to Learned Attractive Odors
}

\author{
D. A. Wilson, R. M. Sullivan, and M. Leon \\ Department of Psychobiology, University of California, Irvine, California 92717
}

\begin{abstract}
Neonatal rats learn to approach odors associated with stimulation normally provided by their mother. The present report describes changes in olfactory bulb single-unit activity following olfactory learning in young rats. Rat pups were exposed from postnatal day 1 to 18 to either (1) peppermintscented air while receiving tactile stimulation (Pepp-Stroked), (2) peppermint-scented air with no tactile stimulation (PeppOnly), (3) clean air and tactile stimulation (Stroked-Only), or (4) clean air and no tactile stimulation (Naive). On day 19, single-unit activity was recorded from mitral/tufted cells in urethane-anesthetized, freely breathing pups in response to either peppermint or a novel orange odor. Mitral/tufted cell response patterns to peppermint were significantly altered in Pepp-Stroked animals compared to control pups. Peppermint exposure alone, not associated with tactile stimulation (Pepp-Only), did not affect subsequent single-cell response patterns to that odor. In addition, the modification of response patterns was specific to peppermint and was not associated with a change in respiration rate. Furthermore, Pepp-Stroked pups had a relative behavioral preference for peppermint on day 19 compared to control pups. These results demonstrate that postnatal olfactory learning selectively modifies the subsequent response patterns of olfactory bulb output cells to the attractive odor. Furthermore, these results indicate that the initial coding of an odor's attractive value occurs within the olfactory bulb.
\end{abstract}

The rat brain is structurally and physiologically immature at birth. In fact, many of the structures and neurophysiological processes believed to be important for learning and memory formation in adult animals are very immature or nonfunctional for the first few postnatal weeks (Thoman et al., 1968; Campbell and Coulter, 1976; Cowan et al., 1981; Rakic and GoldmanRakic, 1982; Harris and Teyler, 1984; Wilson, 1984). However, neonatal rats are capable of learning, (Caldwell and Werboff, 1962; Thoman et al., 1968; Pedersen et al., 1982; Sullivan et al., 1986a, b) and, in some situations, even capable of demonstrating long-lasting memory (Johanson and Hall, 1982; Rudy and Cheatle, 1983). Thus, neonatal animals may be relying on

\footnotetext{
Received Aug. 29, 1986; revised May 1, 1987; accepted May 5, 1987.

This work was supported by Grants BNS 8606786 from the NSF to D.A.W. and M.L. HD 06818 from the NICHD to R.M.S., and NS 21484 from the NINCDS to M.L., who holds RSDA MH 00371 from the NIMH. D.A.W. and R.M.S. would like to thank A.M.S.-W. for contributions to this work.

Correspondence should be addressed to Donald A. Wilson at the above address. Copyright (C) 1987 Society for Neuroscience $0270-6474 / 87 / 103154-09 \$ 02.00 / 0$
}

unique mechanisms for learning and memory storage. The present paper describes some of the changes in single-unit activity associated with postnatal learning, in an attempt to further our understanding of its cellular mechanisms.

The olfactory system was chosen for the present analysis for 2 reasons. First, olfactory-guided behavior appears at birth in Norway rat pups (Alberts, 1976; Rosenblatt, 1983) and is critical for their development and survival. Odor cues play an important role in guiding nipple selection for suckling, the maintenance of maternal and littermate contact, and conspecific identification (Leon and Moltz, 1971; Singh et al., 1975; Leon et al., 1977; Alberts, 1978; Galef and Muskus, 1979; Galef and Kaner, 1980; Pedersen and Blass, 1981; Alberts and May, 1984). Second, the significance of these odors is determined primarily by early learning. Young rats approach the specific maternal odor that they experience early in life (Leon, 1975; Galef and Kaner, 1980) and will even develop an attraction to other, artificial odors (Leon et al., 1977; Alberts, 1978; Brunjes and Alberts, 1979; Galef, 1982; Alberts and May, 1984; Caza and Spear, 1984; Sullivan et al., 1986b). The development of these preferences, however, is strongly dependent on the context in which the odors are experienced. Odor experience associated with tactile stimulation in the litter situation (Galef and Kaner, 1980; Galef, 1982; Alberts and May, 1984), or in an experimental situation that mimics the kind of stimulation received during maternal care (Pedersen et al., 1982; Sullivan and Leon, 1986a; Sullivan et al., 1986b), induces a strong behavioral preference for that odor. Odor exposure alone induces either no odor preference (Pedersen et al., 1982; Sullivan and Leon, 1986a; Sullivan et al., 1986b) or a much weaker one (Galef and Kaner, 1980; Galef, 1982; Alberts and May, 1984).

Several lines of evidence suggest that at least one locus of neural change following olfactory learning is in the olfactory bulb itself. In the mature olfactory bulb, biologically significant odors (Pager et al., 1972; Cattarelli et al., 1977; Astic and Cattarelli, 1982), as well as odors that have gained significance through experience (Pager, 1974; Freeman and Schneider, 1982), induce different patterns and/or levels of bulbar activation than do nonsignificant odors. In young rats, evidence suggests that postnatal odor experience alters the olfactory bulb response to subsequent presentations of that odor, as measured by uptake of ${ }^{14}$-C 2-deoxyglucose (2-DG) (Coopersmith and Leon, 1984; Sullivan and Leon, 1986a) and single-unit recording (Wilson et al., 1985). This altered bulbar response is associated with olfactory learning, rather than with odor exposure alone. Only rat pups exposed to brief daily pairings of an odor and reinforcing (Sullivan and Hall, 1987) tactile stimulation have both an en- 
hanced pattern of olfactory bulb 2-DG uptake and a behavioral attraction upon subsequent presentation of that odor (Sullivan and Leon, 1986a). Pups exposed daily to the odor alone, with no concurrent stimulation, do not demonstrate either the enhanced focal 2-DG uptake or behavioral attraction (Sullivan and Leon, 1986a). In addition, the enhanced focal 2-DG uptake is not mediated by an increase in respiration (Coopersmith and Leon, 1984; Coopersmith et al., 1986; Sullivan and Leon, 1986a), further suggesting that the olfactory bulb itself is modified by olfactory learning.

While these data suggest that the neonatal olfactory system changes in response to postnatal learning, the limited resolution of 2-DG autoradiography provides insufficient information regarding the cellular mechanisms of these changes. The present study, therefore, describes the changes in olfactory bulb activity associated with postnatal olfactory learning by examining the single-unit activity of olfactory bulb output cells. Mitral and internal tufted cells receive direct input from the primary olfactory nerve and are the primary output neurons of the bulb (Shepherd, 1972). The patterns of enhanced metabolic activity associated with olfactory learning, determined previously (Sullivan and Leon, 1986a), were used to guide the microelectrode placement to improve the likelihood of detecting learning-associated changes. The results demonstrate a sclective modification of mitral/tufted cell response patterns following postnatal olfactory learning.

\section{Materials and Methods}

Subjects. Male and female Wistar rat pups, born in our colony, were used. Litters were housed in polypropylene cages filled with pine chips. On the day of birth (postnatal day 0; PN0), litters were culled to 8 pups. Food (TD69466; Teklad, Madison, WI) and water were continuously available. Procedures used to minimize extraneous odor experience during development are described in detail in Wilson et al. (1985).

Olfactory conditioning protocol. Litters were randomly assigned on PN0 to one of 4 conditions: Pepp-Stroked $(n=9)$, Pepp-Only $(n=10)$, Stroked-Only $(n=9)$, and Naive $(n=9)$. Pups were individually exposed for 10 min daily, from PN1 to PN18, to either peppermint-scented air or clean air. Flow-dilution olfactometers were used to obtain clean air or a 1:10 dilution of saturated pcppermint vapor at a flow rate of 7 liters/min. Airstreams were routed from these olfactometers, through separate sets of tubing, into eight $1000 \mathrm{ml}$ glass beakers. The temperature within each beaker was $25^{\circ} \mathrm{C}$. For an odor-exposure session, the litter was removed from its home cage and each animal was placed in a beaker for a $10 \mathrm{~min}$ adaptation period and the $10 \mathrm{~min}$ odor presentation. During the odor presentation, pups in the Pepp-Stroked group were vigorously stroked over their entire body with a sable-hair brush. Stroked-Only pups were stroked in the presence of clean air. Pups in the Pepp-Only group were exposed to peppermint odor but not stroked. Naive pups received no stimulation. The litter was returned to its mother immediately following exposure. On PN19, individual pups were used for either behavioral testing or single-unit recording. Different pups were used for the 2 tests to avoid effects of differential odor exposure during the test.

Behavioral preference test. On PN19, 2 pups from each litter were tested for the development of a behavioral olfactory preference with a 2-odor choice test (Cornwell-Jones, 1979; Johanson and Hall, 1982; Rudy and Cheatle, 1983; Sullivan and Leon, 1986a). The test apparatus consisted of a rectangular Plexiglas box $(43 \times 25 \times 14 \mathrm{~cm})$ with a smallgrid wire mesh $(1 \times 1 \mathrm{~cm})$ floor divided in half by a $2-\mathrm{cm}$-wide neutral zone. Below the mesh, on either side of the neutral zone, were 2 containers. One container was filled with pine shavings scented with peppermint. The other container was filled with clean pine shavings on which the pups had been raised and were thus familiar with. A trial began by placing the pup on the neutral zone, between the 2 odors. When the pup's head and forepaws crossed from the neutral zone into either half of the test box, a timer was started. The total amount of time the pup spent over each of the odors was recorded at the end of the 3 min trial.
Single-unit recording. While variation in stimulus intensity and duration can influence olfactory bulb single-unit response patterns (e.g., Kauer, 1974; Harrison and Scott, 1986; Meredith, 1986), we were concerned here with describing how postnatal conditioning with a specific olfactory stimulus of a specified intensity alters subsequent responses to the identical stimulus. Therefore, the stimulus presented during single-unit recording was identical in quality and intensity to that presented during training, as is standard procedure in conditioning experiments (e.g., Cohen, 1984; Thompson et al., 1984). We also chose to examine single-unit responses under conditions as natural as possible, to preserve the normal response of an animal to a learned odor. Since single-unit recording from the olfactory bulbs of unanesthetized, freely moving 19 . d-old rat pups is not easily performed, we recorded from freely breathing, urethane-anesthetized pups. While respiration rate is depressed in urethane-anesthetized animals (see below), natural respiration ensured a normal pattern of nasal airflow and stimulus delivery to the olfactory mucosa, with a normal temporal relationship to ongoing bulbar activity. In order to determine whether differences in respiration rate before, during, or after the stimulus could account for observed differences between groups in single-unit responses, we monitored respiration in animals in each condition.

One or 2 pups from each litter were used for single-unit recording on PN19. Pups were anesthetized with urethane $(1.5 \mathrm{gm} / \mathrm{kg})$ and mounted in a stereotaxic device. Body temperature was maintained at $35^{\circ} \mathrm{C}$ with a heating pad. Glass microelectrodes (DC resistance in normal Ringer's, 5-12 M 2 ), filled with $2 \mathrm{M} \mathrm{NaCl}$ and saturated fast green, were lowered vertically into the lateral olfactory bulb, $1.5-2.1 \mathrm{~mm}$ from the rostral pole of the bulb, corresponding to the area of 2-DG uptake to peppermint odor (Coopersmith and Leon, 1984; Sullivan and Leon, 1986a). The mitral cell body layer was identified by electrode depth, increased background activity, and electrode position relative to the reversal point of the field potential antidromically evoked from the lateral olfactory tract (LOT). Single-unit activity of presumed isolated mitral/tufted cells was characterized by the ability to elicit spikes by stimulation of the LOT. Spikes were considered to be antidromic if they were evoked at constant latency and could follow at least 4 pulses at $100 \mathrm{~Hz}$. There was no significant difference between groups in mitral/tufted cell antidromic activation latency following single pulses to the LOT. Mean antidromic latency for all cells was $4.1 \pm 0.5 \mathrm{msec}-\mathrm{a}$ long latency compared to that in mature rats, presumably due to the immature level of myelination of the LOT at this age (Schwob et al., 1984; Wilson and Leon, 1986a). Fast green dye was iontophoresed from the recording electrode either at the site of recording or at the end of the electrode track. Recording sites in relation to this dye spot were verified histologically at the end of the recording session. A drawing of a representative section of an olfactory bulb, with the vertical clcetrode track and cell locations marked, is shown in Figure 1. As can be seen, cells recorded in this animal (and all animals) were localized to the mitral cell layer and were near the region of focal 2-DG uptake to peppermint described above, lateral and $1.5-2.1 \mathrm{~mm}$ from the rostral pole of the bulb.

Following isolation of a cell, odor stimuli were delivered through glass tubing from olfactometers (1:10 dilution, $4 \mathrm{l} / \mathrm{min})$ to the external nares of the naturally respiring animal. Peppermint and a novel orange odor were randomly presented for $4 \mathrm{sec}, 3$ times each, if recording stability allowed. The novel orange odor was used to test the specificity of the effects of olfactory conditioning. At least $60 \mathrm{sec}$ elapsed between odor presentations. This delay between stimuli was sufficient to allow firing rates to return to baseline before the next stimulus (baseline firing rate across groups prior to first peppermint stimulus, $\bar{x}=6.4 \pm 0.6 \mathrm{~Hz}$ versus baseline firing rate prior to third peppermint stimulus, $\bar{x}=$ $6.9 \pm 0.7 \mathrm{~Hz}$; dependent $t$ test, $p>0.10$ ). The $4 / \mathrm{min}$ flow rate assured rapid delivery of the stimulus to the naturally respiring animal. The 1: 10 odor dilution matched the stimulus intensity used during training, as described above.

Several response classification schemes exist for descriptive studies of general single-unit response properties, and no single classification scheme is universally accepted (Kauer, 1974; Kauer and Shepherd, 1977; Meredith and Moulton, 1978; Mair, 1982; Chaput and Holley, 1985; Harrison and Scott, 1986; Meredith, 1986). These classification schemes are used to relate changes in single-unit spike trains during odor stimulation to underlying synaptic interactions in the coding of olfactory information. In the present report, however, our main interest was not in describing in detail how spike trains change during odor stimulation, but in detcrmining whether single units in animals with different histories respond differently to an odor under identical test conditions. 
Figure 1. Localization of recordings to lateral mitral cell body layer, 1.5$2.1 \mathrm{~mm}$ from the rostral pole of the bulb. Drawing of a representative section $(30 \mu \mathrm{m})$ of olfactory bulb stained with cresyl violet. Vertical dashed line represents electrode track. Fast green was iontophoresed from the recording electrode at the small circle at bottom of the electrode track. Asterisks correspond to locations of cells sampled along lateral aspect of the bulb. Distance $(\mu \mathrm{m})$ from rostral pole of the bulb is indicated on top ( $\mathrm{ml}$, mitral cell body layer; $g l$, glomerular layer). On the right is a representative spike elicited by antidromic stimulation of the LOT. Ten sweeps superimposed, asterisk marks the stimulus artifact. Calibration, $5 \mathrm{msec}, 200 \mu \mathrm{V}$.
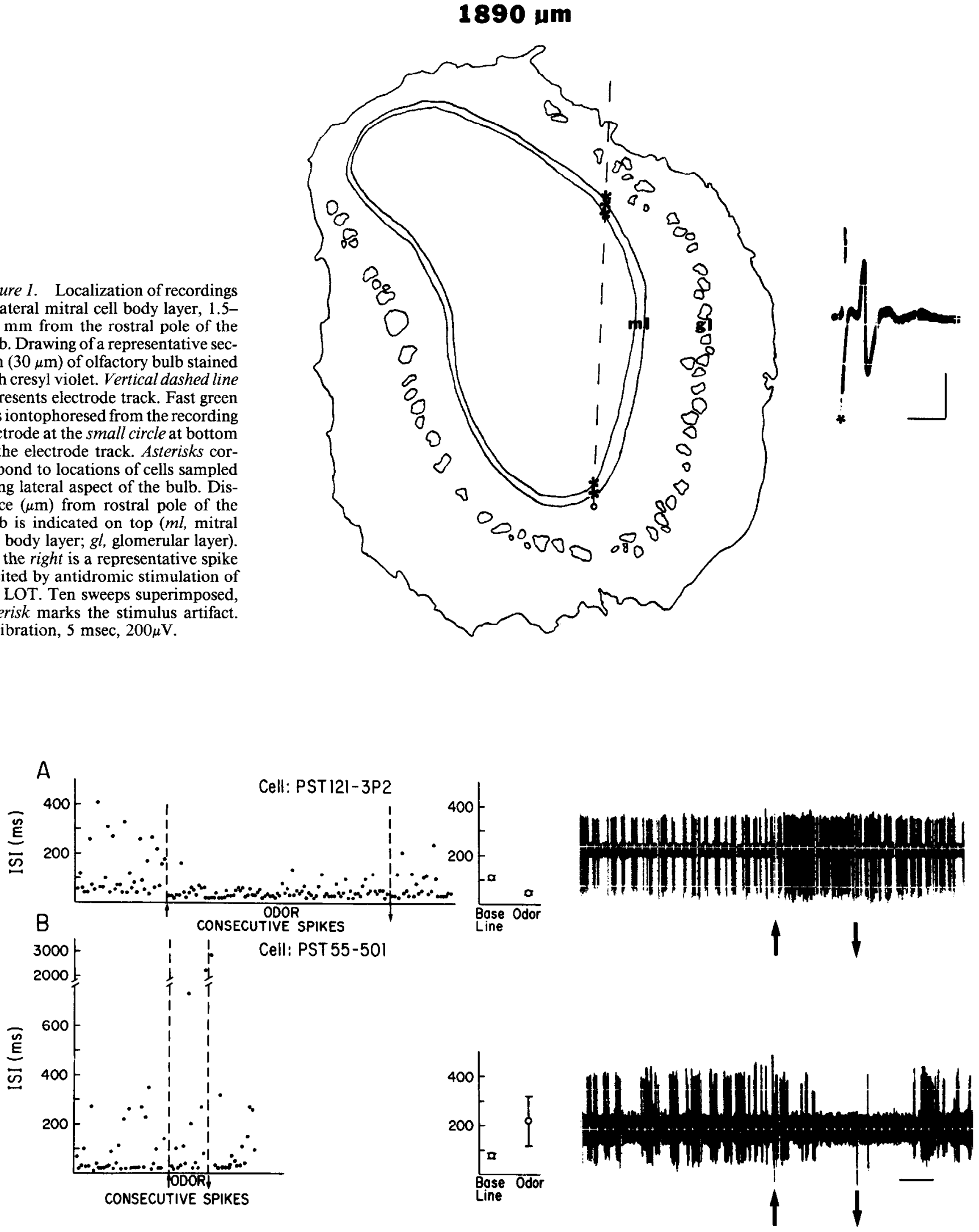

Figure 2. Representative excitatory and suppressive single-unit responses and example of their analysis. $A$, Representative single-unit excitatory response. Peppermint odor presented between arrows. Graph on left represents interspike intervals of consecutive spikes taken from recording on right. Excitatory response is characterized by a decrease in ISI during the odor presentation. Mean ISI ( \pm SE) during $10 \mathrm{sec}$ baseline and $4 \mathrm{sec}$ odor shown in middle graph. $B$, Representative suppressive response characterized by an increase in ISI during the odor. Note large increase in ISI during the odor. Orange odor presented between the arrows. Duration of odor was $4 \mathrm{sec}$ in both $A$ and $B$. Calibration for single unit recordings, 2 sec. 


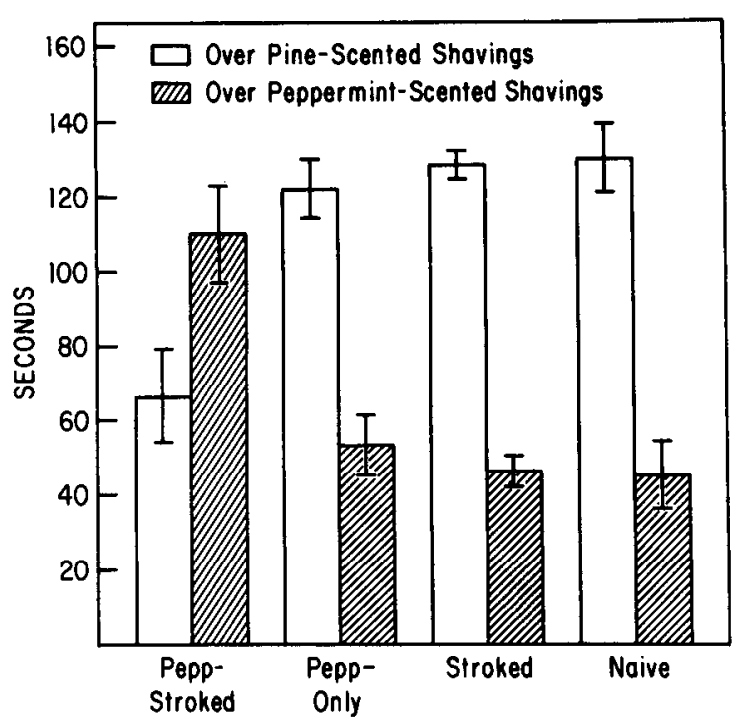

Figure 3. Behavioral preference test. Mean $( \pm$ SE) time spent over peppermint-scented pine shavings and clean pine shavings in a 2-odor choice test for each group. Pepp-Stroked pups spent significantly more time over peppermint than did any control group.

Thus, the critical aspect of the analysis was to allow consistent, unbiased comparisons between groups of single-unit responses to naturally respired olfactory stimuli. The response analysis described below serves this function.

Mitral/tufted cell responses to odors were analyzed with an Apple IIe computer. Interspike intervals (ISIs) were determined during a $10 \mathrm{sec}$ pre-odor baseline, the $4 \mathrm{sec}$ odor presentation, and a 10-30 sec postodor period. The mean ISIs for the baseline and odor periods were compared, and responses to the odor were classified by convention, as excitatory, suppressive, or no response. Responses were defined as follows: (1) Excitation: a decrease (nonoverlapping standard errors) in mean ISI during the odor, compared to the baseline. ISI is the reciprocal of instantaneous firing frequency, and thus a decrease in ISI corresponds to an increase in firing rate. (2) Suppression: an increase in mean ISI during the odor. (3) No response: no change in mean ISI during the odor. Figure 2 displays representative excitatory and suppressive responses. This method of response analysis was found to correspond well with results obtained using peristimulus time (PST) histograms (cf. Wilson et al., 1985). Mean ISI calculation, however, was preferred because it allowed a more quantitative, objective analysis of the responses of even slow-firing neurons. While the criterion of nonoverlapping standard errors does not imply statistical significance, it does allow a constant, conservative estimate of responsiveness across cells. The percentages of excitatory and suppressive responses in relation to the total number of stimulus presentations were calculated for each group and comparisons made between groups using chi-square tests or ANOVAs (Hays, 1981). In addition, the degree of excitation or suppression during individual responses (response magnitude) was calculated and compared between groups. Response magnitude, i.e., the percentage change in ISI during the odor compared to baseline ISI, was calculated as: [(baseline ISI - odor ISI)/baseline ISI] $\times 100$.

Respiration analysis. Single-unit responses to odors can be influenced by the respiration cycle (Macrides and Chorover, 1972; Pager, 1985). Furthermore, respiration rate can be altered by exposure to some odors (e.g., Pager et al., 1972). Thus, in order to determine whether olfactory conditioning modified respiratory responses to the attractive odor, 5 animals from each condition were prepared as described above for single-unit recording; however in addition, a thermistor was implanted into the left nasal passage through a hole drilled in the overlying bone. The thermistor was used to monitor respiration rate during the $10 \mathrm{sec}$ baseline, $4 \mathrm{sec}$ odor stimulus, and $6 \mathrm{sec}$ post-odor periods. Transients in voltage across the thermistor produced by inhalations and exhalations were amplified and passed through a window discriminator set to detect inhalations. The peppermint stimulus was delivered exactly as described above for single-unit analysis, 5 times/animal. Cumulative PST histograms (1 sec bin width) of inhalations were calculated with an Apple IIe computer. Cumulative PST histograms were used to magnify, and

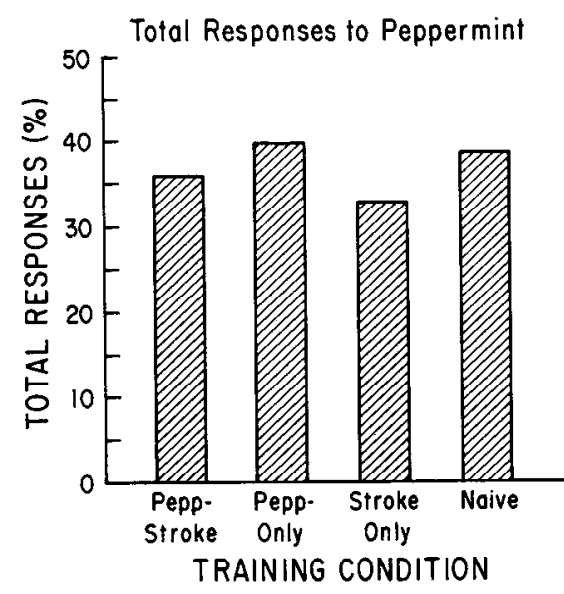

Figure 4. Percentage of cells demonstrating responses (excitatory or suppressive) to peppermint odor. No significant difference was detected between groups in the percentage of cells that were responsive to peppermint odor.

therefore make more detectable, any change in respiration rate that may have occurred in response to the stimulus. The difference between the total number of inhalations for the $4 \mathrm{sec}$ immediately preceding the stimulus and the total number of inhalations during the $4 \mathrm{sec}$ stimulus was determined for each animal and compared between groups using a 1-way ANOVA. Baseline respiration rates were also compared between groups using a 1-way ANOVA.

\section{Results}

\section{Behavior}

Only animals that had peppermint odor experience paired with tactile stimulation from PN1 to PN18 demonstrated a relative behavioral preference for peppermint on $\operatorname{PN} 19(F(3,48)=11.45$; $p<0.001)$. Pepp-Stroked animals $(n=13)$ spent significantly more time over the peppermint-scented shavings than did animals in all 3 control groups, as shown in Figure 3 ( $n=13$ pups/ group; post hoc Tukey tests, $p<0.01$ ). Furthermore, PeppStroked pups spent significantly more time over the peppermint than over the pine odor $(t(24)=2.31 ; p<0.05)$.

\section{Single-unit responses}

A total of 141 cells from 31 pups were examined (Pepp-Stroked: 27 cells from 6 pups, 73 stimulus presentations; Pepp-Only: 46 cells from 10 pups, 119 stimulus presentations; Stroked-Only: 30 cells from 7 pups, 75 stimulus presentations; Naive: 38 cells from 8 pups, 93 stimulus presentations). Three aspects of singleunit responses to the learned attractive odor were compared between groups: overall responsiveness to peppermint (total excitatory and suppressive responses combined), response magnitude (degree of excitation or suppression during individual responses), and the pattern of excitatory and suppressive responses to peppermint. While overall responsiveness and response magnitude were not changed by olfactory learning, the excitatory-suppressive response pattern to peppermint was selectively modified in Pepp-Stroked pups.

Overall responsiveness to peppermint (total excitatory and suppressive responses combined) did not change across groups. The proportion of peppermint stimulus presentations that resulted in a mitral/tufted cell response, as defined in Materials and Methods, ranged from 33\% in Stroked-Only pups to $40 \%$ in Pepp-Only pups (Pepp-Stroked, 36\%; Naive, 39\%; Fig. 4). As described elsewhere (Chaput and Holley, 1985), some cells in each group changed their response type over the 3 stimulus 


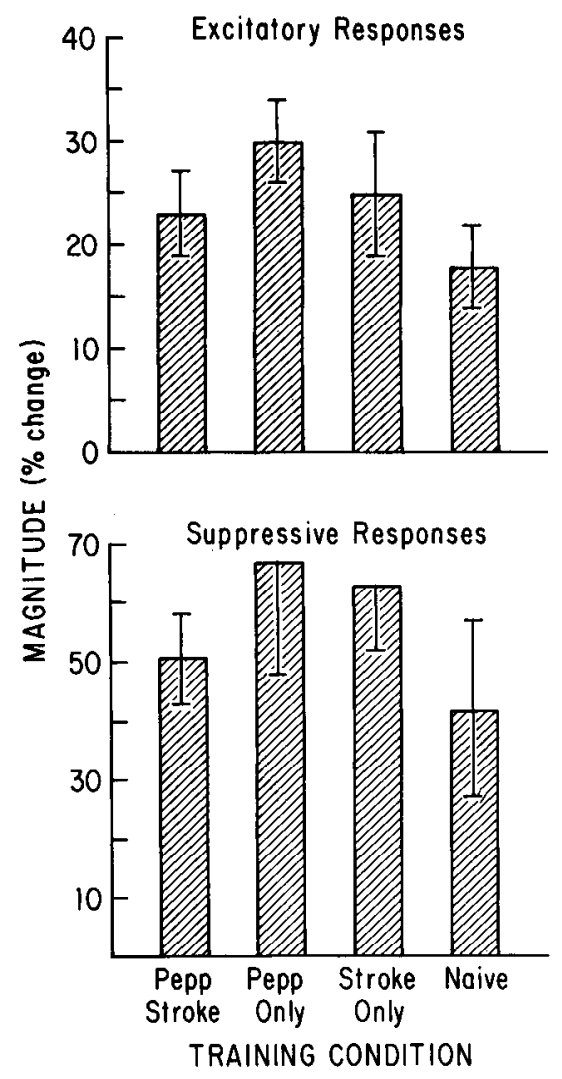

Figure 5. Magnitude of individual excitatory and suppressive responses to peppermint. Percentage change in ISI during the odor stimulus compared to baseline during defined excitatory (top) and suppressive (botlom) responses to peppermint odor. No significant difference was detected between groups. Pepp-Stroked response magnitudes were near the middle of the range of response magnitudes of control groups.

presentations, and were excited for one stimulus and suppressed for another presentation of that same stimulus. This change in response type over repeated stimuli was also not influenced by odor conditioning. Seven percent of cells in Pepp-Stroked pups showed a response change to peppermint, compared to $13 \%$ in Pepp-Only, $10 \%$ in Stroked-Only, and 0\% in Naive pups.

Furthermore, the magnitude of individual excitatory and suppressive responses was not altered by olfactory conditioning
(Fig. 5). The magnitude of excitatory responses to peppermint odor did not differ significantly between groups $(F(3,36)=1.98$; N.S.). Excitatory responses by Pepp-Stroked cells were characterized by a mean $22 \%$ ( $\mathrm{SE}=3 \%$ ) decrease in ISI during the odor presentation (Pepp-Only, 31\% \pm 4 ; Stroked, 21\% \pm 6 ; Naive, $22 \% \pm 3$ ). Suppressive response magnitude also did not differ between groups $(F(3,32)=0.98$; N.S. $)$, with mean increases in ISI during the odor of $45 \% \pm 6$ (Pepp-Stroked), $63 \% \pm 11$ (Pepp-Only), 40\% \pm 9 (Stroked), and 66\% \pm 21 (Naive). For those cells held for all 3 presentations of peppermint, there was no significant change in response magnitude for the first, compared to the third, stimulus (mean excitatory response magnitude across groups: first stimulus $=30 \% \pm 6$, third stimulus $=33 \% \pm 6$; mean suppressive response magnitude: first stimulus $=47 \% \pm 10$, third stimulus $=57 \% \pm 13$ ).

However, the response patterns of mitral/tufted cells to peppermint were significantly modified by Pepp-Stroked training (Fig. 6). Mitral/tufted cells in Pepp-Stroked pups demonstrated significantly fewer excitatory and more suppressive responses to peppermint odor on PN 19 than did cells in either Pepp-Only, Stroked-Only, or Naive animals $(2 \times 2$ chi-square tests; PeppStroked vs controls, $p<0.05$ ). In fact, Pepp-Stroked was the only group to have an excitation-suppression response ratio to peppermint of less than 1.0. That is, Pepp-Stroked cells were more likely to be suppressed than excited by peppermint, while the reverse held for all control groups (Pepp-Stroked, excitation $(\%) /$ supprcssion $(\%)=0.73 ;$ Pepp-Only $=1.67$; StrokedOnly $=2.67 ;$ Naive $=2.25$ ).

The modified mitral/tufted cell response pattern in PeppStroked pups was specific to the attractive odor. No significant difference was seen between groups in response pattern to the novel orange odor (chi-square, N.S.; Fig. 6). Furthermore, excitation-suppression response ratios to orange were greater than 1.0 for all groups (Pepp-Stroked $=1.11$; Pepp-Only - 1.69; Stroked-Only $=1.78 ;$ Naive $=1.23$ ).

These differences in single-unit response pattern do not appear to be due to differential respiration in response to peppermint. There was no significant difference between groups in respiratory response to the peppermint stimulus $(F(3,16)=0.17$; N.S.). In fact, as shown in Figure 7, in only 3 animals ( 2 Pepp-Only and 1 Naive pup) did respiration rate during the stimulus exceed (above or below) baseline variability. In all animals, respiration rate did not vary from baseline more than a total of \pm 2 inhala-
Figure 6. Modified mitral/tufted cell response patterns to an attractive odor. Percentage of excitatory and suppressive responses of mitral/tufted cells to peppermint and orange test odors in each group. Cells in Pepp-Stroked pups exhibited significantly fewer excitatory and more suppressive responses to peppermint than did those of the control groups.

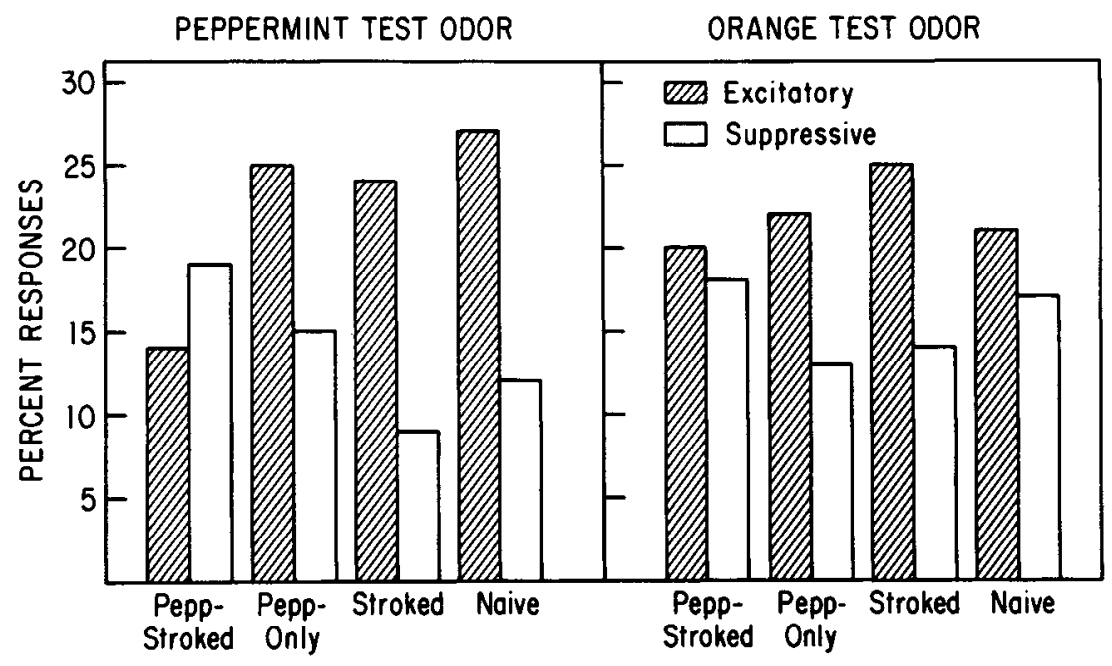




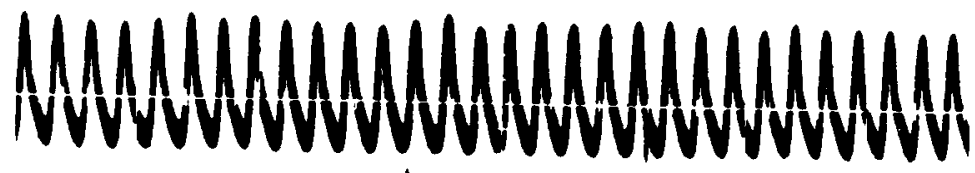 11}

B
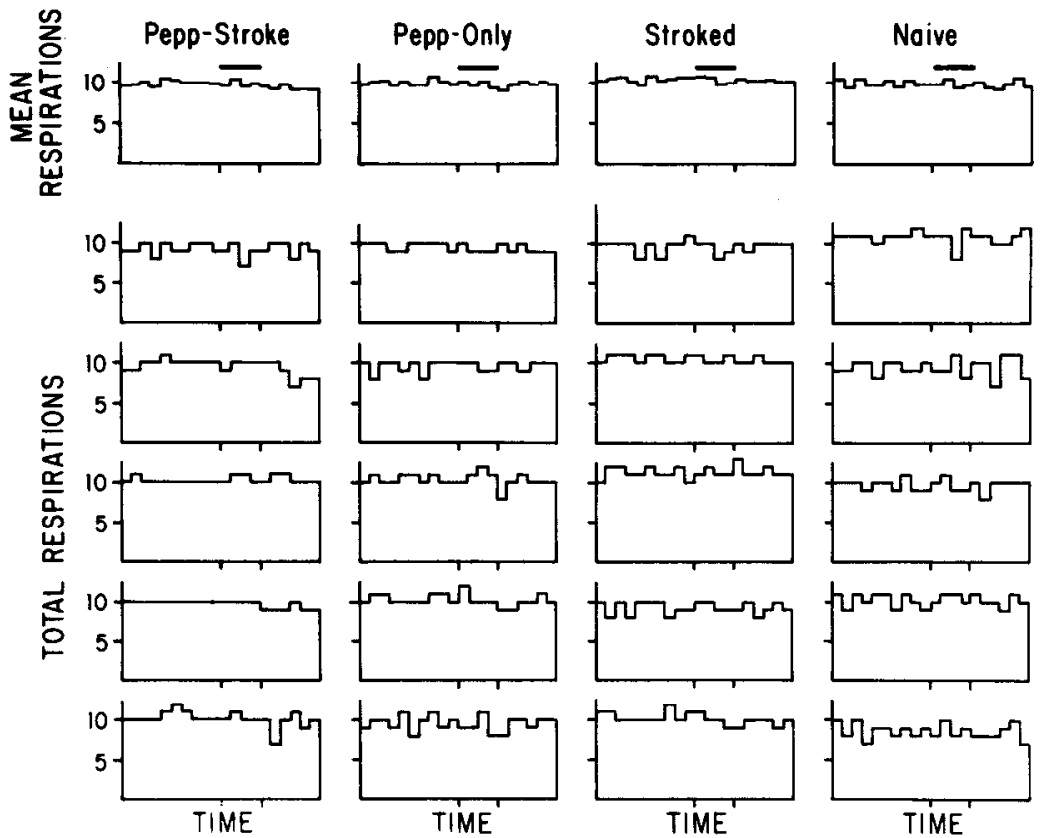

Figure 7. Analysis of respiratory response to the attractive odor. $A$, Representative example of respirations before, during, and after a 4 sec peppermint stimulus; stimulus delivered between the arrows. $B$, Cumulative PST histograms ( $1 \mathrm{sec}$ bin width) from 5 presentations of peppermint. Stimulus presented during horizontal bar. Top row is mean PST histograms for each group, determined from 5 animals whose individual histograms are presented below. Mean respiration rate was $2 \mathrm{~Hz}$; thus, on average, a total of 10 respiration cycles accumulated per second over 5 repetitions.

tions/ $1 \mathrm{sec}$ bin over the course of the 5 stimulus presentations, indicating no consistent effect of the stimulus on respiration. Mean baseline respiration rate did not significantly differ betwecn groups $(F(3,16)=0.77 ;$ N.S. $)$. Mcan respiration ratc was $2 \mathrm{~Hz}$.

The results displayed in Figure 6 were obtained by grouping all odor presentations for all cells within each treatment group, regardless of how many cells or responses were obtained from any particular animal. This has been the standard procedure in research on olfactory bulb responses to odors (Pager et al., 1972; Cattarelli et al., 1977; Wilson et al., 1985). Since this method provides a single percentage of excitatory and suppressive responses for each group, there is no indication of the amount of variability that occurs within groups. Therefore, the data were reanalyzed for individual animals. The percentage of excitatory and suppressive responses to peppermint was calculated for each animal, then combined to give a mean and standard error score for each group. Only animals with at least 5 cells were included in the analysis, to provide an accurate, representative sample of the cells in a given animal. Figure 8 displays the mean percentage $( \pm$ SEM) of excitatory and suppressive responses to peppermint odor in each group, analyzed by animal ( $n=5$ pups/ group). The response pattern to peppermint in Pepp-Stroked animals was significantly different than the pattern in all 3 control groups (2-way ANOVA; response $\times$ treatment interaction, $F(3,32)=5.42 ; p<0.01)$. Pepp-Stroked animals demonstrated significantly fewer excitatory and significantly more suppressive responses to peppermint than did any control group (post hoc Tukey tests, $p<0.05$ ).

\section{Comparison of behavior with physiology}

As described in Materials and Methods, 2 pups from each litter were used for behavioral preference testing and 1-2 pups from the same litter were used for single-unit recording. In order to determine the relationship between the learned behavioral attraction and altered output response pattern to peppermint, a single "excitation score" and an odor preference score were determined for each litter in each group. The excitation score was determined for litters within which more than 5 cells were recorded across animals, and represented the percentage of excitatory responses to peppermint out of the total number of responses to peppermint: [excitatory responses/(excitatory responses + suppressive responses) $\times 100$. The odor preference score was simply the mean time spent over peppermint during the odor preference test ( $180 \mathrm{sec}$ test) by the 2 littermates for that litter. Figure 9 displays the results, with cach point representing a single litter, and with coordinates along the abscissa and ordinate derived from different pups within that litter. Only those litters with the 5-cell minimum criterion are shown. The magnitude of the behavioral attraction to peppermint was signficantly correlated with the mitral/tufted cell response pattern to peppermint across groups $(r=-0.71 ; p<0.01)$. It is important 


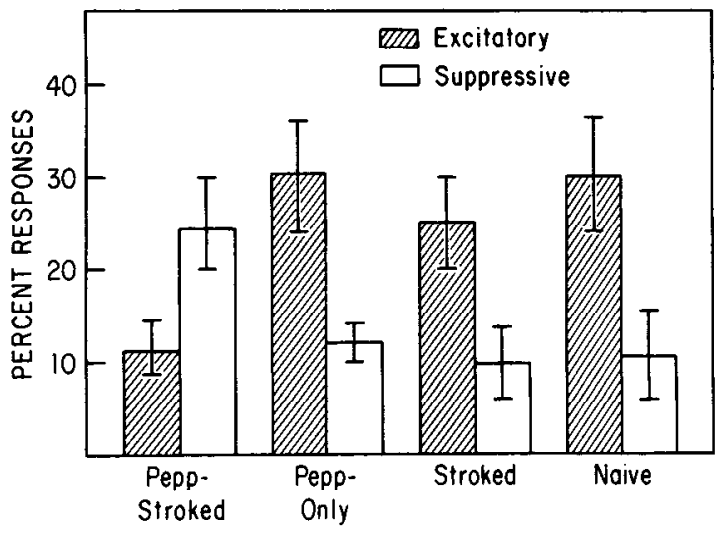

Figure 8. Percentages of excitatory and suppressive responses to peppermint odor in each group, analyzed by animal. Percentages were calculated for individual animals in which 5 or more cells were recorded, then combined across animals to provide a mean $( \pm S E)$ percentage for each group ( $n=5 /$ group). See text for details.

that the single Pepp-Stroked litter that did not demonstrate a strong preference for peppermint odor also did not demonstrate an altered mitral/tufted response pattern to peppermint (PeppStroked, $r=-0.50$ ). Of interest is a similar relationship between behavior and physiology noted in the control pups (combined control litters, $r=-0.50$ ) (Fig. 9).

\section{Discussion}

The present results demonstrate that postnatal olfactory learning is strongly correlated with a selective change in the pattern of subsequent olfactory bulb output responses to that odor. Association of an odor with tactile stimulation resulted both in a behavioral attraction and a modified mitral/tufted cell response pattern to that odor in young rats. Mitral/tufted cells in PeppStroked pups had a selective decrease in excitation and increase in suppression in response to subsequent presentations of the attractive odor. This modified response pattern occurred in the absence of any change in respiration rate.

The urethane-anesthetized pups used for single-unit recording had depressed respiration rates as compared to awake animals at this age (Alberts and May, 1980). Thus, the number of odor molecules reaching the olfactory mucosa during a defined time period, and therefore the intensity and duration of receptor activation during stimulus exposure, may differ between the behaving pups and the anesthetized pups. Since single-unit response patterns can vary with change in stimulus intensity, the exact excitatory-suppressive response patterns observed in the anesthetized pups may not generalize to the awake animal responding to the attractive odor. Nevertheless, the data presented here demonstrate that postnatal olfactory learning modifies single-unit response patterns to that odor in anesthetized conditioncd pups comparcd to anesthctized control pups. This modification cannot be accounted for by differential respiration rates during the stimulus (Fig. 7), and thus must rely on either an intrinsic change in the olfactory system or a change imposed on the olfactory system by other brain structures. We believe it is unlikely that these changes are only expressed under urethane anesthesia, given that in both urethane-anesthetized pups (Sullivan el al., 1987) and awake, freely moving pups (Coopersmith and Leon, 1984; Coopersmith et al., 1986; Sullivan and Leon, 1986) olfactory bulb metabolic responses to learned attractive

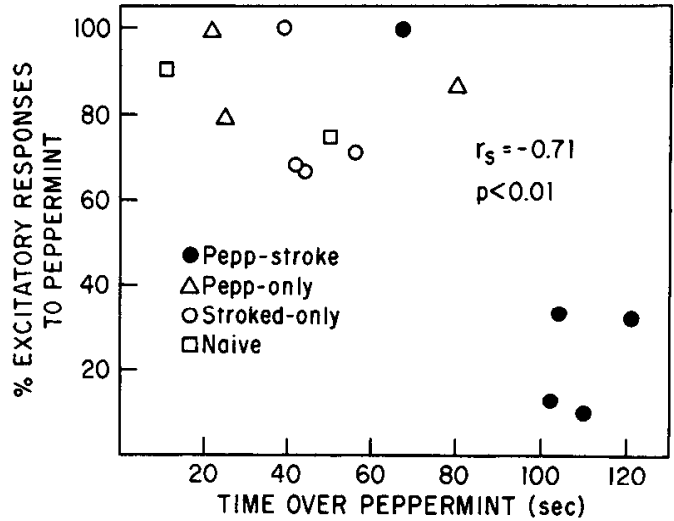

Figure 9. Correlation between the attractive value of an odor and mitral/tufted cell response pattern to that odor. Each point represents a single litter from which at least 5 cells were recorded. Behavioral testing and single-unit recording were performed on different littermates.

odors are modified in the absence of any detectable change in respiratory response. Therefore, we propose that a similar single-unit response pattern modification is expressed in behaving animals.

These results replicate and extend our previous findings (Wilson et al., 1985) by demonstrating that the modification of mitral/tufted cell response patterns is specifically associated with learning, rather than due to mere odor exposure during development or to habituation. These conclusions are evidenced by (1) postnatal odor exposure alone, not associated with tactile stimulation, did not result in either a behavioral attraction or modification of mitral/tufted cell response patterns; (2) the overall responsiveness to the attractive odor (combined excitatory and suppressive responses) did not differ across groups; only the pattern of excitatory and suppressive responses varied; (3) modification of response patterns was specific to the odor paired with tactile stimulation; and (4) the behavioral preference of Pepp-Stroked pups for peppermint. The magnitude of this behavioral preference was significantly correlated across litters with the degree of mitral/tufted cell response modification.

The mechanisms of the altered output cell response patterns are not known. For example, it is not clear whether the changes in mitral/tufted cell activity following olfactory learning are due to changes in the olfactory bulb itself, or to changes occurring elsewhere, which then simply modulate bulbar activity (Leonard, 1981; Freeman and Schneider, 1982). Several possible mechanisms, however, can be postulated. First, it is quite likely that centrifugal inputs to the bulb play an important role in at least the development, and possibly the expression, of this phenomenon. Centrifugal afferents are known to modulate statedependent olfactory bulb responsiveness to biologically significant odors in mature rats (Pager, 1978; Astic and Cattarelli, 1982; Cattarelli, 1982a, b). In addition, postnatal olfactory learning can be disrupted by manipulation of the noradrenergic system (Pedersen et al., 1982; Sullivan and Leon, 1986b). The olfactory bulb contains no intrinsic noradrenergic neurons, but receives a large noradrenergic input from the locus coeruleus (Shipley et al., 1985). Noradrenergic modulation of olfactory bulb excitability develops during the first postnatal week (D. A. Wilson and M. Leon, unpublished observations). Furthermore, neurons in the locus coeruleus can be activated by tactile stimulation (stroking) in rats as young as PN1 (Kimura and Naka- 
mura, 1985), which in turn could modulate olfactory bulb activity during training.

A second possible mechanism of altered mitral/tufted cell response patterns could involve altered olfactory nerve input to the bulb. Respiration rates, and thus the amount of odor reaching the olfactory mucosa, did not differ between groups. However, the affinity or number of "peppermint" receptors may be altered by Pepp-Stroke conditioning. Given the extensive lateral and feedback inhibitory circuits in the bulb, either an increase or a decrease in receptor number or affinity associated with Pepp-Stroke training could account for the present results.

A third possible mechanism is an increase in the sensitivity of the olfactory bulb itself to the attractive odor. In both the amphibian (Doving, 1964; Kauer, 1974) and the mammalian (Mair, 1982; Meredith, 1986) olfactory bulb, identified mitral cells that demonstrate excitatory responses to an odor at low concentrations often exhibit suppressive responses to the same odor at higher concentrations. The suppression to high odor concentrations has been hypothesized to result from increased feedback from granule or periglomerular cells onto mitral cells (Kauer and Shepherd, 1977; Meredith, 1986). Inhibitory circuits are functional in the rat olfactory bulb by the end of the first postnatal week (Wilson and Leon, 1986a, 1987). Thus, in the present case, Pepp-Stroked pups may have an increased sensitivity to peppermint, perhaps through changes in the olfactory receptors (as mentioned above) or in the glomerular synaptic complex (Leon et al., 1987; Woo et al., 1987), and this increased sensitivity could then result in a response pattern in Pepp-Stroked animals similar to that seen only to higher odor concentrations in control animals. In fact, postnatal Pepp-Stroked conditioning does induce a change in glomerular morphology in regions associated with focal 2-DG uptake to peppermint. These glomerular regions are significantly larger than glomeruli in other regions of the bulb and larger than glomerular regions in peppermint-responsive foci of controls (Woo et al., 1987). Leon et al. (1987) have suggested that the increase in the size of the glomerular layer is due either to an increase in the number of external tufted cells or to an increase in the size of their dendritic arbors. The resulting increased tufted cell feedforward input to inhibitory granule cells in Pepp-Stroked rats would produce the modified output cell response pattern reported here. Further support for this hypothesis comes from preliminary results that suggest that the modified mitral/tufted cell response pattern reported here is localized to the regions of enhanced 2-DG uptake associated with the enlarged glomerular region (Wilson and Leon, 1986b). A more detailed examination of mitral/tufted cell responses following olfactory learning, specifically analyzing the temporal aspects of the responses (Kauer, 1974; Kauer and Shepherd, 1977; Meredith and Moulton, 1978; Mair, 1982; Harrison and Scott, 1986; Meredith, 1986) using several stimulus intensities, should help determine the exact mechanisms of this phenomenon.

Whatever the mechanism, the data presented here provide evidence that postnatal olfactory learning is correlated with an altered mitral/tufted cell response pattern to that odor. This learning-associated change in neural activity occurs in olfactory bulb projection neurons that receive direct olfactory receptor input. These results suggest that, in addition to their role in coding for odor quality and quantity, mitral/tufted cells contribute to the coding of an odor's behavioral significance, which can be modified by olfactory conditioning early in life.

\section{References}

Alberts, J. R. (1976) Olfactory contributions to behavioral development in rodents. In Mammalian Olfaction, Reproductive Processes and Behavior, R. L. Doty, ed., pp. 67-94, Academic, New York.

Alberts, J. R. (1978) Huddling by rat pups: Multisensory control of contact behavior. J. Comp. Physiol. Psychol. 92: 220-230.

Alberts, J. R., and B. May (1980) Development of nasal respiration and sniffing in the rat. Physiol. Behav. 24:957-963.

Alberts, J. R., and B. May (1984) Nonnutritive, thermotactile induction of filial huddling in rat pups. Dev. Psychobiol. 17: 161-181.

Astic, L., and M. Catlarelli (1982) Metabolic mapping of functional activity in the rat olfactory system after a bilateral transection of the lateral olfactory tract. Brain Res. 245: 17-25.

Brunjes, P. C., and J. K. Alberts (1979) Olfactory stimulation induces filial huddling preferences in pups. J. Comp. Physiol. Psychol. 93: 548-555.

Caldwell, D. F., and J. Werboff (1962) Classical conditioning in newborn rats. Science 136: 1118-1119.

Campbell, B. A., and X. Coulter (1976) The ontogenesis of learning and memory. In Neural Mechanisms of Learning and Memory, $\mathbf{M}$ R. Rosenzweig and E. L. Bennett, eds., pp. 209-235, MIT Press, Cambridge, MA.

Cattarelli, M. (1982a) Transmission and integration of biologically meaningful olfactory information after bilateral transection of the lateral olfactory tract in the rat. Behav. Brain Res. 6: 313-337.

Cattarelli, M. (1982b) The role of the medial olfactory pathways in olfaction: Behavioral and electrophysiological data. Behav. Brain Res. 6: 339-364.

Cattarelli, M., E. Vernet-Maury, and J. Chanel (1977) Modulation de l'activité du bulbe olfactif en fonction de la signification des odeurs chez le rat. Physiol. Behav. 19: 381-387.

Caza, P. A., and N. E. Spear (1984) Short-term exposure to an odor increases its subsequent preference in preweanling rats: A descriptive profile of the phenomenon. Dev. Psychobiol. 17: 407-422.

Chaput, M. A., and A. Holley (1985) Responses of olfactory bulb ncurons to repeated odor stimulations in awake freely-breathing rabbits. Physiol. Behav. 34: 249-258.

Cohen, D. H. (1984) Identification of vertebrate neurons modified during learning: Analysis of sensory pathways. In Primary Neural Substrates of Learning and Behavioral Change, D. L. Alkon and J. Farley, eds., pp. 129-154, Cambridge U. P., Cambridge, UK.

Coopersmith, R., and M. Leon (1984) Enhanced neural response to familiar olfactory cues. Science $225: 849-851$.

Coopersmith, R., S. R. Henderson, and M. Leon (1986) Odor specificity of the enhanced neural response following early odor experience in rats. Dev. Brain Res. 27: 191-197.

Cornwell-Jones, C. A. (1979) Olfactory sensitive periods in albino rats and golden hamsters. J. Comp. Physiol. Psychol. 93: 668-675.

Cowan, W. M., B. B. Stanfield, and D. G. Amaral (1981) Further observations on the development of the dentate gyrus. In Studies in Developmental Neurobiology: Essays in Honor of Viktor Hamburger, W. M. Cowan, ed., pp. 395-435, Oxford U. P., New York.

Doving, K. B. (1964) Studies of the relation between the frog's electroolfactogram (EOG) and single unit activity in the olfactory bulb. Acta Physiol. Scand. 60: 150-163.

Freeman, W. J., and W. Schneider (1982) Changes in spatial patterns of rabbit olfactory EEG with conditioning to odors. Psychophysiology 19: 44-56.

Galef, B. G., Jr. (1982) Acquisition and waning of exposure-induced attraction to a nonnatural odor in rat pups. Dev. Psychobiol. 15:479_ 490.

Galef, B. G. Jr., and H. C. Kaner (1980) Establishment and maintenance of preference for natural and artificial olfactory stimuli in juvenilc rats. J. Comp. Physiol. Psychol. 94: 588-595.

Galef, B. G., Jr., and P. A. Muskus (1979) Olfactory mediation of mother-young contact in Long-Evans rats. J. Comp. Physiol. Psychol. 93: 708-716.

Harris, K. M., and T. J. Teyler (1984) Developmental onset of longterm potentiation in area CA1 of the rat hippocampus. J. Physiol. (Lond.) 346: 27-48.

Harrison, T. A., and J. W. Scott (1986) Olfactory bulb responses to odor stimulation: Analysis of response pattern and intensity relationships. J. Neurophysiol. 56: 1571-1589. 
Hays, W. L. (1981) Statistics, Holt, Rinehart and Winston, New York, p. 3162 .

Johanson, J. B., and W. G. Hall (1982) Appetitive conditioning in neonatal rats: Conditioned orientation to a novel odor. Dev. Psychobiol. 15: 379-397.

Kauer, J. S. (1974) Response patterns of amphibian olfactory bulb neurones to odour stimulation. J. Physiol. (Lond.) 243: 695-715.

Kauer, J. S., and G. M. Shepherd (1977) Analysis of the onset phase of olfactory bulb unit responses to odour pulses in the salamander. J. Physiol. (Lond.) 272: 495-516.

Kimura, F., and S. Nakamura (1985) Locus coeruleus neurons in the neonatal rat: Electrical activity and responses to sensory stimulation. Dev. Brain Res. 23: 301-305.

Leon, M. (1975) Dietary control of maternal pheromone. Physiol. Behav. 14: 311-319.

Leon, M., and H. Moltz (1971) Maternal pheromone: Discrimination by pre-weanling albino rats. Physiol. Behav. 7: 265-267.

Leon, M., B. G. Galef, Jr., and J. H. Behse (1977) Establishment of pheromonal bonds and diet choice in young rats by odor pre-exposure. Physiol. Behav. 18: 387-391.

Leon, M., R. Coopersmith, S. Lee, R. M. Sullivan, D. A. Wilson, and C. Woo (1987) Neural and behavioral plasticity induced by early olfactory experience. In Perinatal Development: A Psychobiological Perspective, N. A. Krasnegor, E. M. Blass, M. A. Hofer, and W. P. Smotherman, eds., pp. 145-167, Academic, New York.

Leonard, C. M. (1981) Some speculations concerning neurological mechanisms for early olfactory recognition. In Development of Perception: Psychobiological Perspectives, R. W. Aslin, J. R. Alberts, and M. R. Pedersen, eds., vol. 1, pp. 383-410, Academic, New York.

Macrides, F., and S. L. Chorover (1972) Olfactory bulb units: Activity correlated with inhalation cycles and odor quality. Science $175: 84-$ 87.

Mair, R. G. (1982) Responsc properties of rat olfactory bulb neurones. J. Physiol. (Lond.) 326: 341-359.

Meredith, M. (1986) Patterned response to odor in mammalian olfactory bulb: The influence of intensity. J. Neurophysiol. 56: 572597.

Meredith, M., and D. G. Moulton (1978) Patterned response to odor in single neurons of goldfish olfactory bulb: Influence of odor quality and other stimulus parameters. J. Gen. Physiol. 71: 615-643.

Pager, J. (1974) A selective modulation of the olfactory bulb electrical activity in relation to the learning of palatability in hungry and satiated rats. Physiol. Behav. 12: 189-195.

Pager, J. (1978) Ascending olfactory information and centrifugal influxes contributing to a nutritional modulation of the rat mitral cell responses. Brain Res. 140:251-269.

Pager, J. (1985) Respiration and olfactory bulb unit activity in the unrestrained rat: Statements and reappraisals. Behav. Brain Res. 16: $81-94$.

Pager, J., I. Giachetti, A. Holley, and J. Le Magnen (1972) A selective control of olfactory bulb electrical activity in relation to food deprivation and satiety in rats. Physiol. Behav. 9: 573-579.

Pedersen, P. E., and E. M. Blass (1981) Olfactory control over suckling in albino rats. In The Development of Perception: Psychobiological Perspectives, R. N. Aslin, J. R. Alberts, and M. R. Petersen, eds., pp. 359-381, Academic, New York.

Pedersen, P. E., C. L. Williams, and E. M. Blass (1982) Activation and odor conditioning of suckling behavior in 3-day-old albino rats. J. Exp. Psychol. [Anim. Behav.] 8: 329-341.

Rakic, P., and P. S. Goldman-Rakic (1982) Development and modifiability of the cercbral cortcx. Ncurosci. Res. Prog. Bull. 20: 429-611.
Rosenblatt, J. S. (1983) Olfaction mediates developmental transition in the altricial newborn of selected species of mammals. Dev. Psychobiol. 16: 347-375.

Rudy, J. W., and M. D. Cheatle (1983) Odor-aversion learning by rats following $\mathrm{LiCl}$ exposure: Ontogenic influences. Dev. Psychobiol. 16: 13-22.

Schwob, J. E., L. B. Haberly, and J. L. Price (1984) The development of physiological responses of the piriform cortex in rats to stimulation of the lateral olfactory tract. J. Comp. Neurol. 223: 223-237.

Shepherd, G. M. (1972) Synaptic organization of the mammalian olfactory bulb. Physiol. Rev. 52: 864-917.

Shipley, M. T., F. J. Halloran, and J. de la Torre (1985) Surprisingly rich projection from locus coeruleus to the olfactory bulb in the rat. Brain Res. 329: 294-299.

Singh, P. J., A. M. Tucker, and M. A. Hofer (1975) Effects of $\mathrm{ZnSO}_{4}$ irrigation and olfactory bulbectomy on rat pups. Physiol. Behav. 17: 373-382.

Sullivan, R. M., and W. G. Hall (1987) Reinforcement in infancy: Classical conditioning using tactile stroking of intra-oral milk infusions as UCS. Dev. Psychobiol. (in press).

Sullivan, R. M., and M. Leon (1986a) Early olfactory learning induces an enhanced olfactory bulb response in young rats. Dev. Brain Res. 27: 278-282.

Sullivan, R. M., and M. Leon (1986b) Implication of norepinephrine in olfactory learning in infant rats. Soc. Neurosci. Abstr. 12: 124.

Sullivan, R. M., S. C. Brake, M. A. Hofer, and C. L. Williams (1986a) Huddling and independent feeding of neonatal rats can be facilitated by a conditioned change in behavioral state. Dev. Psychobiol. 19: $625-635$.

Sullivan, R. M., M. A. Hofer, and S. C. Brake (1986b) Olfactoryguided orientation in neonatal rats is enhanced by a conditioned change in behavioral state. Dev. Psychobiol. 19: 615-623.

Sullivan, R. M., D. A. Wilson, M. Kim, and M. Leon (1987) Enhanced olfactory bulb response to learned attractive odors in the absence of altered respiratory response. Soc. Neurosci. Abstr. (in press).

Thoman, E., A. Wetzel, and S. Levine (1968) Learning in the neonatal rat. Anim. Behav, 16: 54-57.

Thompson, R. F., G. A. Clark, N. H. Donegan, D. G. Lavond, J. S Lincoln, J. Madden IV, L. A. Mamounas, M. D. Mauk, D. A. McCormick, and J. K. Thompson (1984) Neuronal substrates of learning and memory: A "multiple-trace" view. In Neurobiology of Learning and Memory, G. Lynch, J. L. McGaugh, and N. M. Weinberger, eds., pp. 137-164, Guilford, New York.

Wilson, D.A. (1984) A comparison of the postnatal development of post-activation potentiation in the neocortex and dentate gyrus of the rat. Dev. Brain Res. 16: 61-68.

Wilson, D. A., and M. Leon (1986a) Early appcarance of inhibition in the neonatal rat olfactory bulb. Dev. Brain Res. 26: 289-292.

Wilson, D. A., and M. Leon (1986b) Localized changes in olfactory bulb single unit response to learned attractive odors. Soc. Neurosci. Abstr. 12: 123.

Wilson, D. A., and M. Leon (1987) Abrupt decrease in synaptic inhibition in the postnatal rat olfactory bulb. Dev. Brain Res. 33: 134138.

Wilson, D. A., R. M. Sullivan, and M. Leon (1985) Odor familiarity alters mitral cell response in the olfactory bulb of neonatal rats. Dev. Brain Res. 22: 314-317.

Woo, C. C., R. M. Coopersmith, and M. Leon (1987) Morphological and metabolic changes in the olfactory bulb accompany the enhanced neural response to familiar odors in rat pups. J. Comp. Neurol. (in press). 